Acta Technologica Agriculturae 2

Nitra, Slovaca Universitas Agriculturae Nitriae, 2021, pp. 61-66

\title{
A 4-DOF SCARA ROBOTIC ARM FOR VARIOUS FARM APPLICATIONS: DESIGNING, KINEMATIC MODELLING, AND PARAMETERIZATION
}

\author{
Ali ROSHANIANFARD ${ }^{*}$, Du MENGMENG ${ }^{2}$, Samira NEMATZADEH ${ }^{1}$ \\ ${ }^{1}$ University of Mohaghegh Ardabili, Ardabil, Iran \\ ${ }^{2}$ Henan University of Science and Technology, Luoyang, Henan, China
}

The agriculture industry has faced various challenges nowadays. This research is the first part of a project that presents the designing process, kinematic modelling, and parameterization of a 4-DOF SCARA-type robotic arm specifically designed for work in an agricultural field in terms of seeding, watering, fertilizing, weeding, harvesting, and transporting. The designing of parameters, such as optimum degrees of freedom and component configuration, was done. The kinematic model was calculated using the Denavit-Hartenberg method. The structure of robot was developed for inertia reduction, smooth motion, and torque minimization. The results show that the working space, maximum front access, and side access of developed robotic arm were $11.4 \mathrm{~m}^{2}, 2.9 \mathrm{~m}$, and $2.4 \mathrm{~m}$, respectively. The results indicate that the robot has sufficient surface coverage for defined farm work.

Keywords: smart; crop; robot; tractor; autonomous

The future will be challenge-full for the agriculture industry. The world population is estimated to reach 9.7 billion by 2050; therefore, the food quality and quantity should be doubled (FAO, 2009, 2017). Natural disasters and global warming will influence the total factor productivity of the agriculture industry. The water shortage and pollution, same as rainfall pattern change, will limit the watering methods (Oktem, 2008). The labour shortage will be one of the critical issues worldwide soon (Marinoudi et al., 2019). Less than one percent of the US population will deal with farming by 2050 (Accenture, 2017). The average age of farmers reached 66,58 , and 53 years in Japan, the USA, and Iran, respectively. Farmers also struggle with labour employment costs, including insurance, taxes, and salary (Dorward, 2013).

Digital farming as an interdisciplinary field between robotic and agriculture sciences has many solutions for the mentioned concerns. The digital farming comprises two main parts: precision farming (measuring parameters for data generation), and smart farming (using the generated data for different applications). Many valuable studies were done in this field, i.e. social science on digital and smart agriculture (Klerkx et al., 2019), digital innovation in smart farming (Ayre et al., 2019), innovation in digital farming (Bronson, 2019), and digital farming and ICT (Shibusawa, 2018). It is obvious that farm robots will assist future farmers in many aspects. Multiple researchers have focused on developing a new robotic system to plant, protect, and harvest a variety of crops, such as apple (Lv et al., 2019), orange (Garner et al., 2006), tomato (Li et al., 2019), strawberry (Xiong et al., 2019; Aliasgarian et al., 2015), kiwifruit (Williams et al., 2019), grape (Luo et al., 2018), heavy-weight crops (Roshanianfard et al., 2018;
Kamata et al., 2018; Roshanianfard and Noguchi, 2017, 2018b; Roshanianfard, 2018), and pumpkin (Roshanianfard and Noguchi, 2016, 2018a).

The manipulation system and robotic arm as the main component of a robotic system play a significant role in the smart operation. Most of the developed systems were installed on a prototype platform which meets many limitations in real farms. Several researchers installed controlling systems on commercialized platforms, such as tractors (Wang and Noguchi, 2019), combines (Zhang et al., 2013), boats (Liu et al., 2017), all-terrain-vehicles, utility vehicles (UTVs), and drones for farm applications (Roshanianfard et al., 2019; Kashkarov et al., 2018). However, the development of robotic arms and manipulation systems for the aforementioned platforms still requires extensive research. Furthermore, it is worth mentioning that the majority of commercialized robotic arms have not been developed for agriculture in dusty, dirty, and humid environments. They require indoor and isolated working environment.

In this regard, the development of a specifically designed robotic arm, which would be installed on the autonomous tractors working in real agricultural field is a new area (Cviklovič et al., 2016). The research objective is to design a robotic arm that can handle the unpredictable farm situation such as rain, wind, dust, mud, and vibration with an optimized number of degrees of freedom (DOF). Therefore, it can be concluded that the novelty of designed robotic arm is in:

1. its adaptability to real agricultural farm conditions because of its specifically designed components (joints, links, and controlling unit), resilient against vibration, dust, and humidity; 


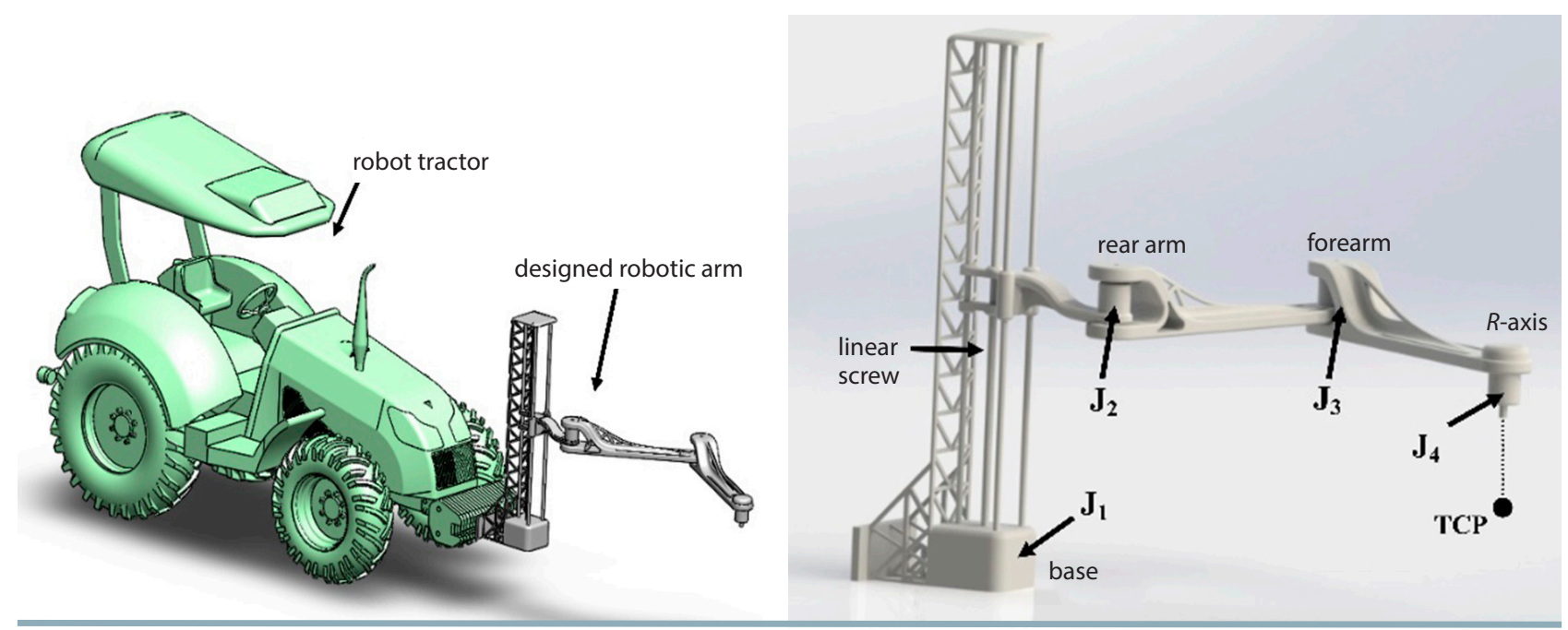

Fig. 1 Robotic system for real agricultural field (left), and designed robotic arm (right)

2. specifically simplified quick algorithm for collaboration with an autonomous tractor with minimum delay;

3. its sufficient payload per weight compared with industrial robotic arms.

\section{Material and methods}

\section{Designed system}

Based on the mentioned concerns in farming, a 4-DOF SCARA type robotic arm was designed, as shown in Fig. 1. The 3D CAD design was done using Solidworks (Dassault Systèmes, France). First, several configurations and structures of robotic arms were searched and evaluated from different points of view, including the number of joints, working space, access length, orientation of endpoint, and strength of elements. Multiple simulations were performed in order to reach an optimized structure. As the objective of this research was developing a robotic arm for farm use, a vertical orientation through the Z-axis along the front and lateral access was required. The simplicity of orientation can make the structure manufacturing process and algorithm development much easier. The designed robotic arm is equipped with a linear screw to move in the $Z$-direction. This axis will be used when the robot transports a crop or when it wants to change the structure height. The robotic arm also has three more joints for the rear arm, forearm, and rotation of end-effector (EE). These three joints move the EE in the $X$ - and $Y$-directions. The material applied for the body was aluminium (AL5052), because the light aluminium alloy used shows good weldability by gas, arc, and resistance. The structure design and all simulations were conducted for $20 \mathrm{~kg}$ of payload and 1.5 of the factor of safety (FOS).

\section{Configuration and coordination}

The agricultural farms and horticultural environments are complicated, unstructured, and dirty environments. This is especially true for robotic arms with multiple sensitive components, such as servo motors, amplifiers, cables, and control units. Because of that, it is important to develop a robotic arm with simple and repairable components. Moreover, it is important to shield all electronic and electrical parts; design stainless joint and component; and use specifically selected ball bearing and bearings. This simplicity in structure makes the algorithm development much easier. Therefore, after DOF selection process, a SCARA type robotic arm with a 4-DOF was designed, as shown in Fig. 1. This robotic arm has 4 joints: $J_{1}, J_{2}, J_{3}, J_{4}$. Each joint was designed for a different task. The $J_{1}$, connected to a long screw, can control the position of endpoint in Z-axis. The $J_{2}$ and $J_{3}$ move the rear arm and forearm, respectively, and control the endpoint in $X$ - and $Y$-directions. Ultimately, the $J_{4}$ was set specifically for rotating the attached EE. The designed robot can manoeuvre in a $3 \mathrm{D}$ environment smoothly and it can perform the majority of agriculture operations, i.e. seeding, watering, fertilizing, weeding, and harvesting, etc. The coordination of joints and

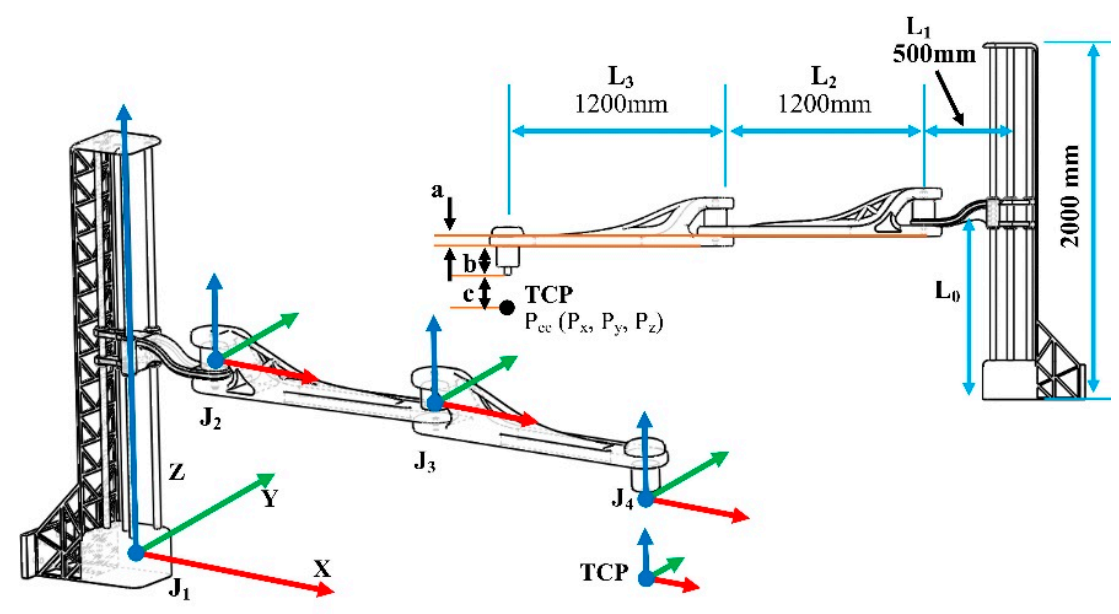

Fig. 2 Coordination of robotic arm (left), parameter description (right) 
home coordination were adjusted based on the righthanded coordinate system, as shown in Fig. 2. The rotations in $X-, Y$-, and $Z$-direction were named roll $\left(r_{x}\right)$, pitch $\left(r_{y}\right)$, and yaw $\left(r_{z}\right)$, respectively.

\section{Kinematics of robot}

\section{Forward kinematics}

After numerous calculations using different methods, the Denavit-Hartenberg (D-H) method was selected because of its simplicity and quick response. Using the D-H method allows for setting the rotation angles $J_{1}, J_{2}, J_{3}, J_{4}$ and tool offsets as input; and for obtaining a position in $X_{-}, Y_{-}$, and $Z$-directions $\left(P_{x^{\prime}} P_{y^{\prime}}\right.$ and $P_{z^{\prime}}$ respectively), orientation $\left(r_{x^{\prime}}, r_{y^{\prime}}, r_{z}\right)$ of tool centre point (TCP) and angle of each joint as outputs. As the motion in the Z-axis depends only on the rotation of $J_{1}$, the $L_{0}$ can be calculated as follows:

$$
\begin{gathered}
L_{o}=I\left(n+\frac{\theta_{1}}{360}\right)=I \cdot n+\beta \cdot \theta_{1} \\
n=\left\lceil\frac{P_{z}}{l}\right\rceil \text { and } \beta=\frac{I}{360}
\end{gathered}
$$

where:

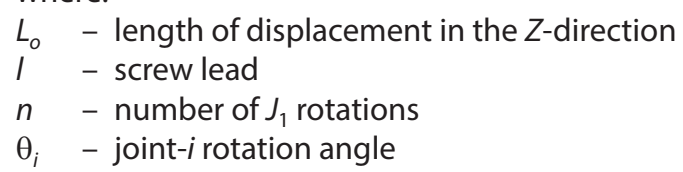

Then:

$$
P_{z}=I\left(n+\frac{\theta_{1}}{360}\right)
$$

Therefore, the position of TCP in the 3D environment can be resulted as:

$$
\begin{gathered}
P_{x}=L_{1}+L_{2} \cos \theta_{2}+L_{3} \cos \left(\theta_{2}+\theta_{3}\right) \\
P_{y}=L_{2} \sin \theta_{2}+L_{3} \sin \left(\theta_{2}+\theta_{3}\right) \\
P_{z}=L_{o}-a-b-c
\end{gathered}
$$

where:

$$
\begin{aligned}
& P_{i} \quad-\text { position of endpoint in the } i \text {-direction } \\
& \begin{aligned}
a, b, c- & \text { offset between the } J_{2} \text { and } J_{3} \text {, the } J_{3} \text { and } J_{4} \text {, and the } \\
& J_{4} \text { and EE } \\
\theta_{n} \quad-\quad \text { angle of joint- } n \text {. The rest of the parameters is } & \text { illustrated in Fig. } 2
\end{aligned}
\end{aligned}
$$

\section{Inverse kinematics}

The forward kinematic calculation is a progressive task that is performed to find the position of EE from a variation of joint angles. To develop a robotic arm, one of the timeconsuming and hard tasks is to find the desired joint angle if the EE's position is input. This section presents the inverse kinematics calculation of designed robotic arm.

Let set the position and orientation in the $X_{-}, Y_{-}$, and $Z$-directions as $P_{x^{\prime}} P_{y^{\prime}}$ and $P_{z^{\prime}}$ respectively, and $r_{x^{\prime}} r_{y^{\prime}}$ and $r_{z}$ of TCP as inputs, and rotation angle of joints $J_{1}, J_{2}, J_{3}$, and $J_{4}$, and tool offsets as outputs. Based on Eqs 4-6, it is possible to calculate each angle continuously. The $\theta_{1}$ is calculable using Eq. 6:

$$
\theta_{1}=\left(\frac{P_{z}+a+b+c}{\beta}\right)-2 n \pi=\left(P_{z}-a-b-c\right) \cdot\left(\frac{2 \pi}{l}\right)-l \cdot n
$$

To calculate the $\theta_{3}$ by means of Eqs 4 and 5, there is:

$$
\begin{gathered}
L_{2} \cos \theta_{2}+L_{3} \cos \left(\theta_{2}+\theta_{3}\right)=P_{x}-L_{1}=A \\
L_{2} \sin \theta_{2}+L_{3} \sin \left(\theta_{2}+\theta_{3}\right)=P_{y}=B
\end{gathered}
$$

By $(\text { Eq. } 4)^{2}+(\text { Eq. } 5)^{2}$, then:

$$
\begin{gathered}
\left(L_{2} \cos \theta_{2}+L_{3} \cos \left(\theta_{2}+\theta_{3}\right)\right)^{2}+ \\
\left(L_{2} \sin \theta_{2}+L_{3} \sin \left(\theta_{2}+\theta_{3}\right)\right)^{2}=A^{2}+B^{2}
\end{gathered}
$$

Subsequently:

$$
\cos \theta_{3}=\frac{A^{2}+B^{2}-L_{2}^{2}-L_{3}^{2}}{2 L_{2} L_{3}}
$$

From Eq. 11:

$$
\sin \theta_{3}=\sqrt{1-\left(\frac{A^{2}+B^{2}-L_{2}^{2}-L_{3}^{2}}{2 L_{2} L_{3}}\right)^{2}}
$$

Using Eqs 11 and 12:

$$
\theta_{3}=\arctan 2\left( \pm \sqrt{1-\left(\frac{A^{2}+B^{2}-L_{2}^{2}-L_{3}^{2}}{2 L_{2} L_{3}}\right)^{2}} \cdot \frac{A^{2}+B^{2}-L_{2}^{2}-L_{3}^{2}}{2 L_{2} L_{3}}\right)
$$

To calculate $\theta_{2}$ by means of $\cos \theta_{2}$. Eq. $8+\sin \theta_{2}$. Eq. 9 , there is:

$$
A \cdot \cos \theta_{2}+B \cdot \sin \theta_{2}=L_{2}+L_{3} \cdot \cos \theta_{3}
$$

Using $-\sin \theta_{2}$. Eq. $8+\cos \theta_{2}$. Eq. 9, there is:

$$
-A \cdot \sin \theta_{2}+B \cdot \cos \theta_{2}=L_{3} \cdot \sin \theta_{3}
$$

Using $A \cdot$ Eq. $15+B \cdot$ Eq. 16 , there is:

$$
\cos \theta_{2}=\frac{A\left(L_{2}+L_{3} \cdot \cos \theta_{3}\right)+B \cdot L_{3} \cdot \sin \theta_{3}}{A^{2}+B^{2}}
$$

From Eq. 16:

$$
\sin \theta_{2}= \pm \sqrt{1-\left(\frac{A\left(L_{2}+L_{3} \cdot \cos \theta_{3}\right)+B \cdot L_{3} \cdot \sin \theta_{3}}{A^{2}+B^{2}}\right)^{2}}
$$

Since the range of rear arm is $\left(-90^{\circ},+90^{\circ}\right)$, then the $\cos \theta_{2}$ can be calculated using Eqs 17 and 18:

$$
\begin{array}{r}
\theta_{2}=\arctan 2\left(\sqrt{1-a\left(\frac{A\left(L_{2}+L_{3} \cdot \cos \theta_{3}\right)+B \cdot L_{3} \cdot \sin \theta_{3}}{A^{2}+B^{2}}\right)^{2}},\right. \\
\left.\frac{A\left(L_{2}+L_{3} \cdot \cos \theta_{3}\right)+B \cdot L_{3} \cdot \sin \theta_{3}}{A^{2}+B^{2}}\right) \text { when } P y \geq 0
\end{array}
$$




$$
\begin{array}{r}
\theta_{2}=\arctan 2\left(\sqrt{1-\left(\frac{A\left(L_{2}+L_{3} \cdot \cos \theta_{3}\right)+B \cdot L_{3} \cdot \sin \theta_{3}}{A^{2}+B^{2}}\right)^{2}},\right. \\
\left.\frac{A\left(L_{2}+L_{3} \cdot \cos \theta_{3}\right)+B \cdot L_{3} \cdot \sin \theta_{3}}{A^{2}+B^{2}}\right) \text { when } P y<0
\end{array}
$$

The orientation of EE is always toward the Z-direction, and the angle of $J_{4}$ does not affect the orientation of TCP. It can only affect the rotation of EE during grasping.

\section{Results and discussion}

\section{DOF selection and economic optimization}

Roshanianfard et al. (2020) presented a method for finding an optimized number of DOF for a robotic arm. Based on that methodology, it is necessary to evaluate an invariant structure (with constant main parameters) under different conditions. For this robot, the overall length of links $\left(L=\sum_{i=0}^{n} L_{i}=6 a\right)$, and the height of the installation position ( $h=1.5 a$ ) were considered constant (Fig. 3). At constant $L$ and $h$, the number of joints, type of joints, and DOF were varied, and the results were compared, as shown in Fig. 4. The $a=20 \mathrm{~cm}$ and all parameters were simplified based on this unit. All ratios were adjusted based on the designed robotic arm parameters. The length of the main link was $6 a$, which was equally divided in order to reach the desired n-DOF.
The aim was the simulation and comparison of workspace index $\left(I_{v}=\frac{V_{n}}{a^{3}}\right)$, harvesting surface index $\left(I_{s}=\frac{S_{n}}{a^{2}}\right)$, minimum front access $\left(F A_{\min }\right)$, and height length $(H L)$. As shown in Fig. 4, the workspace of 1-DOF and 2-DOF was zero, because this DOF could move at Fig. 5 , the $I_{v}, I_{s}$, and $H L$ were increased when the DOF increased from 3 to 5 , and the $F A_{\min }$ decreased. The $H L$ of 3-DOF was less than required. This parameter increased between 4-DOF and 5-DOF, making the 4- and 5 -DOF suitable in terms of physical point of view.

The economic and energy aspects of different DOF were the same as presented by Roshanianfard et al. (2019) research (Fig. 6). However, this evaluation took into account different expense sources, i.e. actuating cost, material cost, manufacturing expenses, mechanical parts, electronic component prices, and energy consumptions. Each parameter was calculated based on Japanese market price and then the indices (such as actuator index (price per $100,000 ¥$ ), material index (price per $100,000 ¥$ ), manufacturing index (price per 100,000 $¥$ ), mechanical index (price per $100,000 ¥$ ), electronic index (price per $100,000 ¥$ ), energy price index (required power price per $100,000 ¥)$ ) were measured and compared with the harvestable surface $\left(S_{n}\right)$ and $H L$. As the results indicated, economic and energy indices increased by DOF growth. With an increase in the DOF, the number of required actuator (servo motor), amplifier, connection cables, joint components, control components, and manufacturing time are also increased. More servo motor required more energy and connection

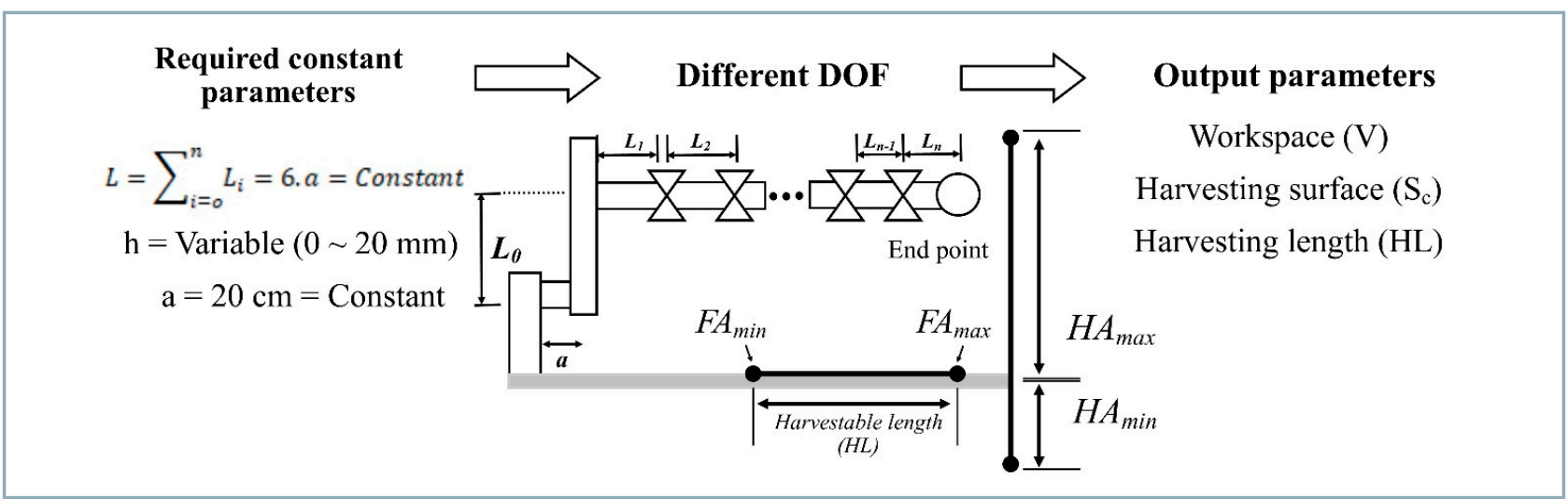

Fig. 3 DOF optimization methodology

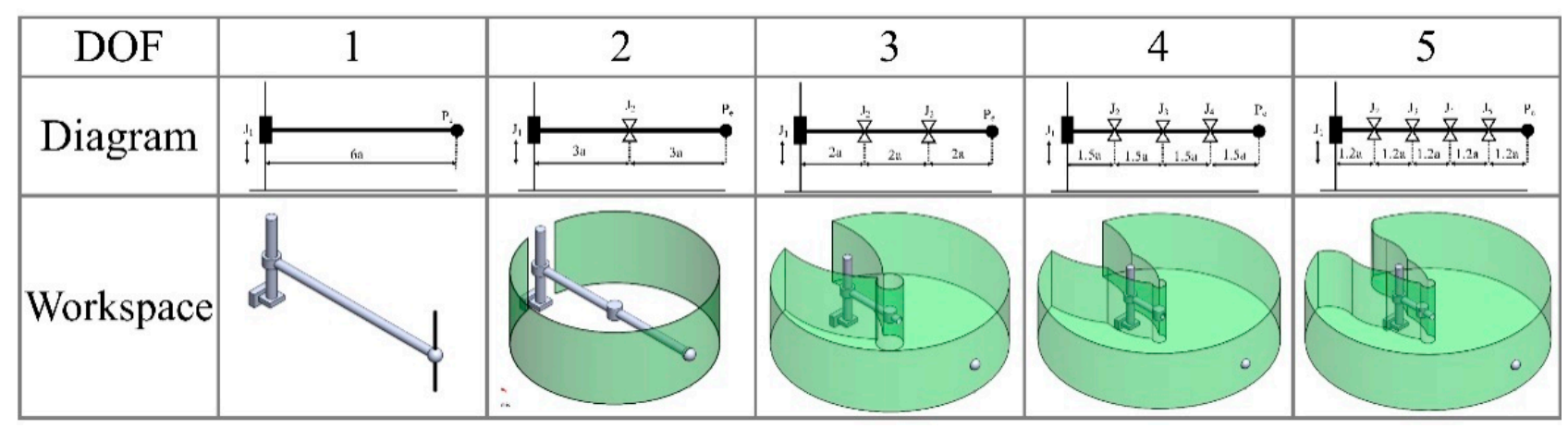

Fig. 4 Comparison of different DOFs in the workspace 
cable; furthermore, the controlling algorithm got also more complex. However, increasing the DOF from 4 to 5 did not increase the $I_{s}$ and $H L$ significantly. Therefore, the 5-DOF robotic cannot be an optimized structure for described application and required parameters. In considering the

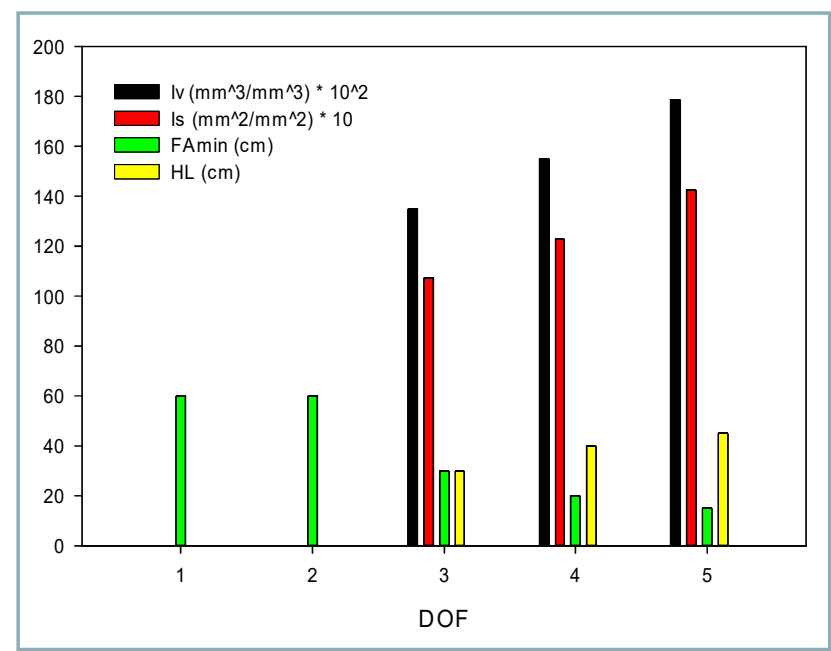

Fig. 5 Required parameters in different DOFs

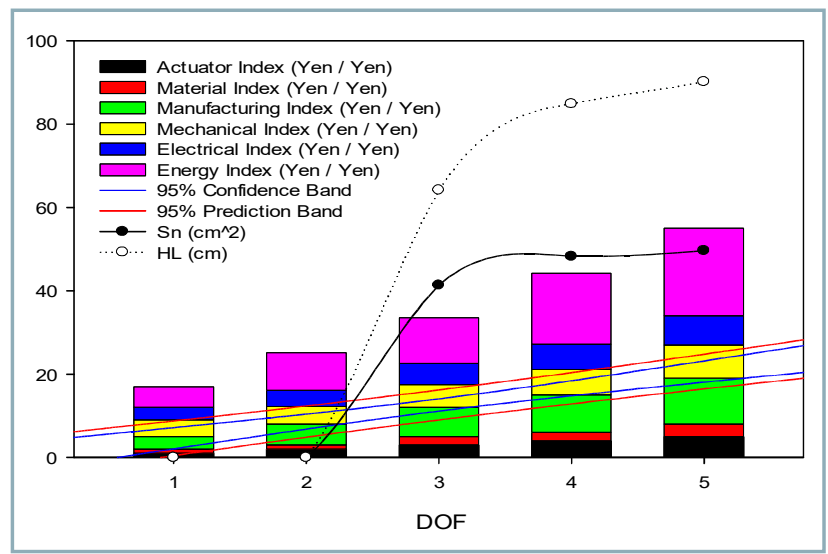

Fig. 6 Economic optimization indices constant length and different DOF, a 4-DOF could be an adequate structure that can support a maximum $V_{n}$ and $S_{n}$ at the minimum cost. Based on these evaluations, a 4-DOF structure was selected to develop a harvesting robotic system.

\section{Working space}

After developing the controlling algorithm, the robot working space resulted based on kinematic equations, as shown in Fig. 7. The designed robotic arm should be able to manoeuvre in the field and move aside tractors for reloading harvested crops in a truck or predetermined elevator on the right or left tractor side. Based on that, the working space should reach a long distance aside from Fig. 7, the designed robotic arm can reach $2.9 \mathrm{~m}$ and $2.4 \mathrm{~m}$ in the $X$ - and $Y$-directions, respectively, the workspace area is $11.4 \mathrm{~m}^{2}$, and $L_{1}, L_{2}$ and $L_{3}$ are 500, 1,200; and 1,200; respectively. The $L_{i}$ is the length of link number-i. By increasing the values of $L_{1}, L_{2}, L_{3}$, it is possible to increase the working space, but it is important to consider the torque value on each joint due to the weight and distance increases. Furthermore, by increasing the length of each link, the inertia applied increases due to velocity during acceleration and deceleration.

\section{Conclusion}

In this paper, a 4-DOF SCARA type robotic arm was designed for agriculture application using the Solidworks software; this arm is capable of carrying out the farm works, such as seeding and planting of various crops using different EEs, performing a variety of farming tasks, including minimal cultivation, watering, fertilizing, spraying, and weeding; and doing selective harvesting for various crops. The forward and inverse kinematics calculation were conducted based on the designed robotic arm calculation and the controlling algorithm was written in Visual $\mathrm{C}++$ using the equations. In a complementary paper, the dynamic simulations and calculations identical to the controlling algorithm will be presented.

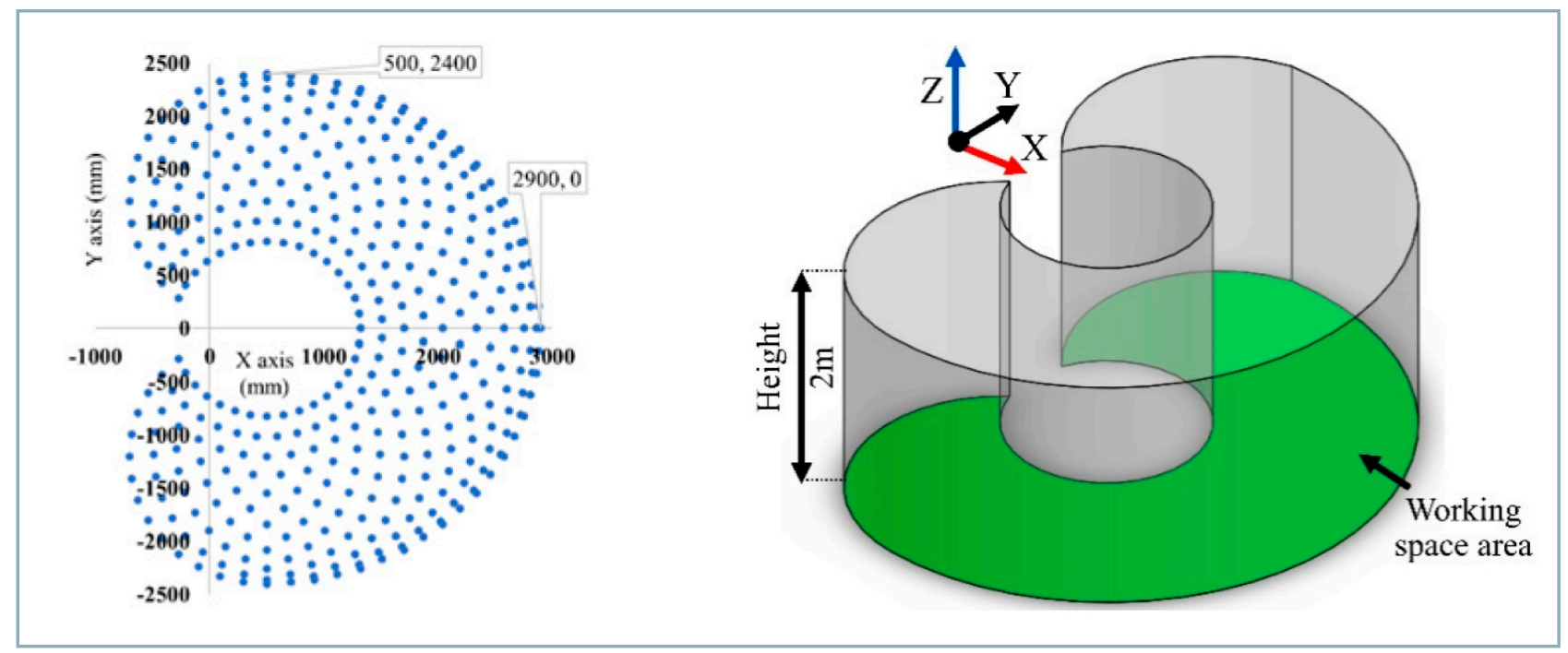

Fig. 7 Working space of designed robot, top view (left), 3D view (right) 


\section{References}

ACCENTURE. 2017. The Future of Food: New Realities for the Industry Available at: https://www.accenture.com/us-en/ acnmedia/pdf70/accenture-future-of-food-new-realities-for-the-industry.pdf ALIASGARIAN, S. - GHASSEMZADEH, H. R. - MOGHADDAM, M. GHAFFARI, H.2015. Mechanical damage of strawberry during harvest and postharvest operations. In Acta Technologica Agriculturae, vol. 18, no. 1, pp. 1-5.

AYRE, M. - MC COLLUM, V. - WATERS, W. - SAMSON, P. - CURRO, A. - NETTLE, R. - PASCHEN, J. A. - KING, B. - REICHELT, N. 2019. Supporting and practising digital innovation with advisers in smart farming. In NJAS - Wageningen Journal of Life Sciences, vol. 90-91, no. December, pp. 100302.

BRONSON, K. 2019. Looking through a responsible innovation lens at uneven engagements with digital farming. In NJAS - Wageningen Journal of Life Sciences, vol. 90-91, no. December, pp. 100294.

CVIKLOVIČ, V. - OLEJÁR, M. - HRUBÝ, D. - PALKOVÁ, Z. - LUKÁČ, O. HLAVÁČ, P. 2016. Navigation algorithm using fuzzy control method in mobile robotics. In Acta Technologica Agriculturae, vol. 19, no. 1 , pp. 19-23.

DORWARD, A. 2013. Agricultural labour productivity, food prices and sustainable development impacts and indicators. In Food Policy, vol. 39, pp. 40-50.

FAO. 2012. Global Agriculture Towards 2050. Available at: http:// www.fao.org/fileadmin/templates/esa/Global_persepctives/ world $\mathrm{ag}_{2} \underline{03}_{5} \underline{2}_{2} \underline{012 \text { rev.pdf }}$

FAO. 2017. The Future of Food and Agriculture - Trends and Challenges. Rome, $163 \mathrm{pp}$.

GARNER, J. P. - MEEHAN, C. L. - FAMULA, T. R.- MENCH, J. A. 2006 Genetic, environmental, and neighbor effects on the severity of stereotypies and feather picking in Orange-winged Amazon parrots (Amazona amazonica): An epidemiological study. In Applied Animal Behaviour Science, vol. 96, no. 1-2, pp. 153-68.

KAMATA, T. - ROSHANIANFARD, A. - NOGUCHI, N. 2018. Heavyweight crop harvesting robot - controlling algorithm. In IFACPapersOnLine, vol. 51, no 17, pp. 244-49.

KASHKAROV, A. - DIORDIIEV, V. - SABO, A. - NOVIKOV, G. 2018. Semi-autonomous drone for agriculture on the tractor base. In Acta Technologica Agriculturae, vol. 21, no. 4, pp. 149-52.

KLERKX, L. - JAKKU, E. - LABARTHE, P. 2019. A review of social science on digital agriculture, smart farming and agriculture 4.0: New contributions and a future research agenda, In NJAS Wageningen Journal of Life Sciences, vol. 90-91, pp. 100315.

LI, Z. - MIAO, F. - YANG, Z. - WANG, H. 2019. An anthropometric study for the anthropomorphic design of tomato-harvesting robots. In Computers and Electronics in Agriculture, vol. 163, no. December, pp. 104881.

LIU, Y. - NOGUCHI, N. - ROSHANIANFARD, A. 2017. Simulation and test of an agricultural unmanned airboat maneuverability model. In International Journal of Agricultural and Biological Engineering, vol. 10, no. 1 pp. 88-96.

LUO, L. - TANG, Y. - LU, Q. - CHEN, X. - ZHANG, P. - ZOU, X. 2018. $A$ vision methodology for harvesting robot to detect cutting points on peduncles of double overlapping grape clusters in a vineyard. In Computers in Industry, vol. 99, pp. 130-139.

LV, J. - WANG, Y. - XU, L. - GU, Y. - ZOU, L. - YANG, B. - MA, Z. 2019. A method to obtain the near-large fruit from apple image in orchard for single-arm apple harvesting robot. In Scientia Horticulturae, vol. 257 , no 17 , pp. 108758
MARINOUDI, V. - SØRENSEN, C. G. - PEARSON, S. - BOCHTIS, D. 2019. Robotics and labour in agriculture. A context consideration. In Biosystems Engineering, vol. 184, pp. 111-21.

OKTEM, A. 2008. Effect of water shortage on yield, and protein and mineral compositions of drip-irrigated sweet corn in sustainable agricultural systems. In Agricultural Water Management, vol. 95, no. 9, pp. 1003-1010.

ROSHANIANFARD, A. 2018. Development of a Harvesting Robot for Heavy-Weight Crop, Ph.D. Thesis, Hokkaido University.

ROSHANIANFARD, A. - KAMATA, T. - NOGUCHI, N. 2018. Performance evaluation of harvesting robot for heavy-weight crops. In IFACPapersOnLine, vol. 51, no. 17 pp. 332-338.

ROSHANIANFARD, A. - NOGUCHI, N. 2016. Development of a 5DOF robotic arm (RAVebots-1) applied to heavy products harvesting. In IFAC - Papers OnLine, vol. 49, no. 16, pp. 155-160.

ROSHANIANFARD, A. - NOGUCHI, N. 2017. Development of heavy-weight crops robotic harvesting system (HCRHS). In The $3^{\text {rd }}$ International Conference on Control, Automation and Robotics (ICCAR 2017). Tokyo, Japan.

ROSHANIANFARD, A. - NOGUCHI, N. 2018a. Characterization of pumpkin for a harvesting robot. In IFAC - Papers OnLine, vol. 51, no. 17, pp. 23-30.

ROSHANIANFARD, A. - NOGUCHI, N. 2018b. Kinematics analysis and simulation of a 5DOF articulated robotic arm applied to heavy products harvesting. In Tarim Bilimleri Dergisi, vol. 24, no. 1, pp. 91-104.

ROSHANIANFARD, A. - NOGUCHI, N. - OKAMOTO, H. - ISHII, K. 2020. A review of autonomous agricultural vehicles (the experience of Hokkiado University). In Journal of Terramechanics, vol. 91, pp. 155-183.

ROSHANIANFARD, A. - NOGUCHI, N. - KAMATA, T. 2019. Design and performance of a robotic arm for farm use. In International Journal of Agricultural and Biological Engineering, vol. 12, no. 1, pp. 146-158.

SHIBUSAWA, S. 2018. Digital farming approach changes the context. In IFAC-PapersOnLine, vol. 51, no. 17, pp. 67-69.

WANG, H. - NOGUCHI, N. 2019. Navigation of a robot tractor using the centimeter level augmentation information via Quasi-Zenith Satellite System. In Engineering in Agriculture, Environment and Food, vol. 12, pp. 414-419.

WILLIAMS, H. A. M. - JONES, M. H. - NEJATI, M. - SEABRIGHT, M. J. BELL, J. - PENHALL, N. D. - BARNETT, J. J. - DUKE, M. D. - SCARFE, A. J. - AHN, H. S. - LIM, J. - MACDONALD, B. A. 2019. Robotic kiwifruit harvesting using machine vision, convolutional neural networks, and robotic arms. In Biosystems Engineering, vol. 181, pp. 140-156. XIONG, Y. - PENG, C. - GRIMSTAD, L. - FROM, P. J. - ISLER, V. 2019. Development and field evaluation of a strawberry harvesting robot with a cable-driven gripper. In Computers and Electronics in Agriculture, vol. 157, pp. 392-402.

ZHANG, Z. - NOGUCHI, N. - ISHII, K. - YANG, L. - ZHANG, C. 2013. Development of a robot combine harvester for wheat and paddy harvesting. In IFAC Proceedings Volumes, vol. 46, no. 4, pp. 45-48. 